over 1000 pilgrims of different nationalities, among whom were a few cases of cholera. These pilgrims underwent their quarantine at Camaran, and no further cases, as far as I know, have been reported among them. Discussions on the subject in the past have usually been very unsatisfactory and the conclusions very indefinite. The serious fact remains that cholera epidemics among the pilgrims annually collected at Mecca are of very frequent occurrence and are a standing menace to Egypt and Europe. Four times within the last twelve years the disease might have been introduced by the pilgrims into Egypt or Europe, or both, and the experience of France and Spain has shown how easily it may become endemic. The endeavours of the Quarantine Board have fortunately been successful in stamping out the disease before the pilgrims reached Egypt. The doings of the Board have been very severely criticised in England-often rightly, but oftener undeservedly and without connaissance de cause. Its actions in the future will be very much modified by the decisions of the Conference of Venice-a conference entirely due to the action of some of the members of the Board who took the initiative and drew up a programme for their government with a view to settle on a more rational basis and smooth over the ever-irritating question of Suez Canal quarantine.

Alexandria.

\section{PITYRIASIS RUBRA IN A CASE OF DIABETES.}

\section{BY HERBERT H. HORDEN, M.D. LOND.}

Pityriasis RUBRa, also sometimes called exfoliative dermatitis, is a rare disease and, unlike most skin affections, involves the whole surface of the body. The occurrence of this disease in a diabetic subject, so far as I can ascertain, has not been previously recorded, and therefore I have thought it sufficiently interesting to publish the case in some detail. That eczema is a complication of diabetes is well known, and since some authorities are inclined to regard pityriasis rubra as a form of eczema the association of the two diseases in the present case is of interest.

The patient, a woman aged seventy, consulted me on May 27th, 1892, on account of great irritation and burning of the lower part of the body. She stated that she had been troubled with it for two or three weeks, but, hoping that it would pass off, she had not taken any pains in treating it, having only applied some ointment, which had given her no relief. On inquiring into her past history I was told by her that she had always led a very active life and had been very healthy and temperate. There was no history of gout or rheumatism in her family. She had noticed during the last few months that she had been growing languid and exhausted, particularly after any exertion, and that though her appetite was very good and at times even ravenous she was losing flesh. Thirst was not complained of, but on closer inquiry it was discovered that she consumed a considerable quantity of water during the night. She complained of her rest being disturbed at night by her having to get up so many times to micturate. She also complained of constipation. On examination the patient appeared to be Wealthy, though the skin of the face was somewhat flabby and loose, giving one the idea that there had been loss of fesh. It was, however, quite free from any eruption. The eyes were carefully examined, but, with the exception of a well-marked arcus senilis, there was nothing abnormal to be detected in the lenses or discs. The skin on the chest and extremities was distinctly dry and somewhat harsh, but with this exception it was normal; on the abdomen, however, extending from midway between the umbilicus and pubic symphysis, there was a well-defined area of a deep-red colour covered with an innumerable number of very thin papery scales overlapping each other, very easily detached, and sxtending to the vulva. The area was very dry to the touch, and there were no crusts to be seen. She complained of great heat and burning over this part, as well as of much irritation. Physical examination of the chest and abdomen revealed nothing abnormal. She was told to measure the quantity of urine passed during the next twenty-four hours and to send a specimen of it to be tested. The amount was determined to be nine pints. It was of a light amber colour and quite clear, and there were no deposits. The specific gravity was 1034. There was no albumen, but Fehling's solution showed the presence of sugar, which was subsequently estimated to be eight grains to the ounce. The patient was not seen for a fortnight, when I was summoned to her house. The rash had then spread over the whole of the abdomen and the lower part of the chest, as well as over the whole of the back, buttocks, and upper parts of the thighs. She said that it was spreading daily and always did so from the edges. Around the edges were seen numerous well-defined red patches, which were slightly raised above the general surface of the skin. Those nearest to the edges were covered with scales and appeared to run into each other, while those more distant had but few scales. In this manner the rash appeared to spread all over the body, including the face and scalp, and also the soles of the feet and palms of the hands. The ears and eyelids were likewise affected. The scales on the face were much smaller than those of the body. The rash took six weeks to envelop the whole body. When the scalp was attacked the hair rapidly fell out, so that the patient became quite bald. When the scales were removed from any part the subjacent skin was intensely red and very tender to the touch. They had everywhere the same character, being, namely, very thin, papery, and imbricated, and not glued together. They appeared to form again almost as soon as removed. The nails of the hands and feet were not affected. The quantity of scales which were shed daily was estimated to be about a pint and a half. The patient complained of great tingling, burning, and heat all over the body, and also of her eyes smarting so much that sbe was obliged to wear a shade to protect them from the light, which seemed to irritate them.

The treatment of the case consisted in keeping the patient confined to one room raised to a moderate temperature, and, during the acute stage, in bed. All draughts were excluded as far as possible, as it was found that she felt the cold keenly. She was put on a strictly diabetic diet, and no wines or malt liquors were permitted, but claret was allowed. Pills containing codeia were ordered three times a day. The local treatment consisted of a calamine liniment composed of calamine, oxide of zinc, and olive oil. This was constantly applied all over the body by soaking lint in the liniment and then winding it round the patient's body and limbs, while it was also dabbed over her face. Each morning the scales were brushed off with a soft brush. The local treatment was faithfully carried out by a daughter, who acted as nurse to the case, and who also looked after the diet. After the rash had become general arsenic was given internally and its effect watched for fourteen days, but as it certainly did no good it was discontinued and the dose of codeia increased. After four months' treatment, by which time the sugar had quite disappeared, the skin affection began to improve, particularly on the legs, but the burning and tingling of the skin increased. For this a mixture containing gelsemium and quinine was prescribed, which gave marked relief. The parts to become well last were the front of the chest and under the breasts. The hair, which had completely fallen off the scalp, has now grown thickly and sbundantly. The skin at the present time is quite free from any eruption, but feels finer and thinner than before the illness, and the patient is very susceptible to cold and perspires freely. The whole duration of the affection was about nine months. Water-lare, Brixton.

\section{HIGH TENSION, HEADACHE, AND ALBUMINURIA.}

\section{By H. WILLOUGHBY GARDNER, M.D., L.R.C.P. LOND.,} M.R.C.S. ENG.

A MAN aged thirty-five came to me on April 6th, 1891, complaining of severe recurrent headaches from which he had suffered since boyhood. He stated that his father had suffered from similar headaches all his life, and that at the age of fifty-eight he began to suffer from softening of the brain, became more and more irritable and strange, and eventually died from that disease at the age of sixty-five. He said he was very like his father in temperament and physique, and his fear was that he himself would eventually suffer from similar brain disease, and that too at an earlier age. Twelve years ago he had suffered from "brain fever," which lasted for six weeks, and during which he had been delirious and unconscious. He recovered completely. He had had no other illness. There was no history of syphilis. His mother, 
vrotber, and three sisters were alive and well. There was so other family history of headache or of gout. The beadache occurred every few weeks. He could suggest no cause for it. It usually lasted all one day, but occasionally for as long as three days.' Of late the attacks had been more serere, but not more frequent. The pain was situated in the occiput and posterior half of the vertex. Rarely it axtended along the right temporal region and occasionally to the forehead, but then it seemed to be of a.different character. it usually began gradually and steadily increased until the erening, when it would be at the worst. It would generally go away with sleep, which it did not prevent. It was described as being intense, the brain seeming to be throbbing against the skull. At times he would turn giddy and his head rould seem to swim. It was never accompanied by aither nausea or vomiting. He knew of no exciting cause, and had no worry or anxiety and very little exposure. When frst seen he was free from headache, and it was nearly a week since the last attack. He was a thin, pale, weakly iooking man, with a high, dome-shaped, narrow head. The reins of his forehead, especially the median, were full. The cemporal arteries were abnormally visible and very tortuous. His tongue was indented; his pulse was 72 and not quite egular; the radial artery was full between the beats and could be rolled beneath the finger, but could be easily com. pressed. No definite thickening of the walls of the vessel could be made out. The heart's apex was in the normal position; the first sound was good; the aortic second sound was accentuated and somewhat ringing in character. The urine was of sp. gr. 1015, faintly acid, and contained a distinct trace of albumen. He passed from three to four pints a day and did not have to get up during the night. He complained of slight dimness of vision at times and wore spectacles, but when tested he could see $\frac{6}{6}$ and read Jaeger 1 . By the ophthalmoscope nothing abnormal was to be seen, and in the eves, at any rate, there was no thickening of the arterial walls. On April 23rd the urine was of sp. gr. 1015, acid, and contained a distinct trace of albumen. On the $26 \mathrm{th}$ he was suffering from severe headache. His bowels had been regular all the week previously, but had only acted slightly on the 25 th and not at all that morning. His pulse was 78 and somewhat irregular in rate. The vessel was small. The beat was weak and could be easily stopped, but the artery was full between the beats and stood out like a cord. The aortic second sound was greatly accentuated and was of a markedly inging character. The urine was of sp. gr. 1015, acid, and contained a thick cloud of albumen. Its quantity was also said to be greater, but no exact measurements were taken. There were no casts, nor were any found at any time, although carefully searched for. Fifteen grains of antipyrin had no appreciable effect upon the headache. Sext morning (the 27th) the headache was gone; the pulse was 102 and was no longer full between the beats, and the aortic second sound had completely lost its ringing character. The urine was of sp. gr. 1014, acid, and contained only the faintest trace of albumen. The bowels had been open twice pretty freely on the evening of the previous day. It being evident that in this case the headache and the albuminuria were intimately connected with high arterial tension, treatment was directed to obviate that condition on the lines laid down by Sir W. H. Broadbent; constipation was especially guarded against, and beer was forjidden. The result has been most satisfactory. Two years and a half have now elapsed. Mr. Charles Flemming of Freshford, his medical attendant, has kindly investigated the case for me, and reports that the patient has been practically free from headache ever since, only having one occasionally, when he has allowed himself to become constipated, or has taken beer again, and then they are never so severe as they formerly were. The patient volunteered the statement that his sight was much better. The pulse was 72 and regular; it still shows considerable tension, but the apex beat is still normal in position, and there is no increased cardiac impulse. The urine is of $\mathrm{sp}$. gr. 1014, and contain no albumen, no casts, and $1 \cdot 1$ per cent. of urea ; from two to three pints are passed daily.

Remarks.--It is evident that in this case high tension, albuminuria, and headache were intimately associated. Whether the headache was due to the high tension directly or whether both were due to some poison in the blood, the result either of deficient metabolism or deficient eliminaion, is uncertain. The concomitant marked increase in altumen might suggest that the headaches were uræmic ; but the increase in the amount of urine would be against that supposition. It seems, perhaps, to be most probable that they were directly due to the high tension. The administration of amyl nitrite might have thrown light on the question, but unfortunately it was not tried. The same problem exists with regard to the relationship of the albuminuria and the high tension. In either case the practical point was to resort to treatment calculated to lessen the excessive pulse tension by preventing the accumulation in the blood of those waste products which might cause it. What these waste products are is another problem. It is worthy of note in this connexion that beer always did, and still does, have a tendency to bring on an attack. So also does constipation, as in the particular attack investigated. It is to be noted that this one came to a close with two rather loose actions of the bowel in the evening, which, it may be inferred, helped to eliminate the poison from the blood. Would the condition, if it had been allowed to go on, have resulted in chronic interstitial nephritis? Most probably. Probably some actual kidney change had already occurred, for the urine was, and still is, of rather low specific gravity, and the urea is still deficient in quantity, and at that time albumen was constantly present. Casts, howerer, though carefully searched for, were never found, and there wero no ophthalmoscopic changes. But, granting that chronic nephritis would have supervened, is this condition a common precursor of that insidious disease, and could the onset of the latter be often suspected and prevented by treatment tending to obviate excessive high tension? Then there is the question of heredity. High tension is known to be markedly hereditary. In this case it seems to be quite clear that the father suffered from headaches of a similar nature and that he was eventually overtaken by some results of vascular degeneration in the brain, causing death. The patient was probably quite right in fearing some similar ending for himself. Curiously enough, the mother has this year been suffering from epistaxis and headache herself, which, Mr. Flemming tells me, he found to be associated with excessive high tension and with urine of sp. gr. of 1011, containing a very faint trace of albumen. The question of heredity would seem to be quite clear were it not that high tension and troubles resulting therefrom are very common in the neighbourhood of the patient's residence; and it is quite curious how many cases of old hemiplegia, apparently from cerebral hæmorrhage, one meets with there. What the cause of it is I do not in the least know ; but it may be that, whatever it is, the patient, his father, and his mother were especially exposed to its action. The fact is to be noticed that, though he no longer suffers from the effects of excessive tension, he still remains a high-tension subject. However this may be, it is, I think, highly satisfactory to find that the headache, the tendency to arterial degeneration, leading inevitably to the shortening of life, the albuminuria, and the probable onset of chronic nephritis could be remedied by the recognition and treatment of the excessive pulse-tension, whatever its cause and its precise connexion with the other symptoms may have been. Swan Hill, Shrewsbury.

\section{Clinital atotes:}

MEDICAL, SURGICAL, OBSTETRICAL, AND THERAPEUTICAL.

\section{THE TREATMENT OF HABITUAL ABORTION BY CHLORATE OF POTASSIUM.}

By Edward F. Pratt, L.R.C.P. Lond.

As far as I am aware there have as yet been no published cases where the treatment of habitual abortion by chlorate of potassium has been successful or even mentioned. I have, therefore, recorded the histories of the two following cases in the hope that they may be useful to brother practitioners, who, I trust, will try the remedy in their own practice should opportunity offer. Both cases were remarkable in that, although there had been nine premature confinements in the one instance and three in the other, yet after persevering with the chlorate of potassium the delivery of a living child at full term was the result in each case. In my own case there is another interesting point-viz., that although I was continually 